\title{
Optimization of Hybrid AC/DC Microgrid in Grid-Connected Mode
}

\author{
Nabil Qachchachi, Hassane Mahmoudi, Abdennebi El Hasnaoui
}

\begin{abstract}
The instability of the production of renewable energy resources (RESs) is a major problem for its installation and integration with the utility grid. A hybrid AC/DC microgrid facilitates the good operation of RESs with a storage system in grid-tied mode and the possibilities of smart energy management. The present work is being carried out on smart control strategy for a hybrid AC/DC microgrid (HMG). This paper deals with a real-time Hybrid control system (HCS) for a grid-connected HMG where the supervisory control based totally on fixing an optimization hassle objectives to minimize operating cost with the maximum usage of renewable resources, minimum usage of the utility grid, extending energy storage systems (ESS) lifetime. The power references for renewable energy resources (RESs) are scheduled by the use of CPLEX solver which uses as input strength measurement, archived facts and stored climate forecast statistics previously measured regarding the modern status. The experimental study verifies well the supervision methodology; thus, the proposed algorithm respects the optimization in real-time operation under different constraints.
\end{abstract}

Keywords: hybrid ac/dc microgrid, optimization, CPLEX, mixed-integer programming.

\section{INTRODUCTION}

The intellectual concept can be achieved easily in microgrids (MGs) [1]. The RESs are mainly used as microgeneration in the microgrid to cover the power demands of buildings and even small population areas. In this paper, the case of a HMG is examined. A microgrid consisting of the two sub-grids (AC and DC grid) allows AC network elements such as AC generation and loads and DC network elements, such as batteries, fuel cells, PV arrays, wind and DC loads, etc. to be separated. The transfer of power between DC and AC links lead to the good functioning of the power system below different conditions of generations and loads [2] [3]. The DC and AC buses are linked by bidirectional interlink converter wish transfers power. The role of the battery is also very important not only for temporal shifting of energy but also for reliability purposes. The battery allows energy imports from the grid and renewable sources (PV arrays and wind) to be stored to be used at opportune times. The role of

Revised Manuscript Received on March 17, 2020.

* Correspondence Author

Qachchachi Nabil*, Electrical Engineering Department, Mohammedia Engineering School, Mohammed-V University, Rabat, Morocco.

Mahmoudi Hassane, Electrical Engineering Department, Mohammedia Engineering School, Mohammed-V University, Rabat, Morocco.

Abdennebi El Hasnaoui, Electromechanical Department, Rabat School of Mines, Rabat, Morocco.

(C) The Authors. Published by Blue Eyes Intelligence Engineering and Sciences Publication (BEIESP). This is an open access article under the CC BY-NC-ND license (http://creativecommons.org/licenses/by-nc-nd/4.0/) the battery as a reserve wish to increase microgrid reliability, for several hours is also considered. In this context, this paper presents a mixed-integer linear programming (MILP) optimization of a grid-tied HMG power flow employing multi-layer power management [4] [5] of the system as shown in figure 1.

\section{SMART HYBRID AC/DC MICROGRID}

A Hybrid AC/DC Microgrid (HMG) increases system efficiency by reducing processes of multiple reverse conversions and facilitating the connection of various RESs and loads to the grid. An Intelligent HMG in grid-tied mode, presented as in [6], was studied in this paper. The management of the HMG Is proposed as a multi-layer shape of local power control, as described in figure 2, based on information approximately the user's criteria request, weather forecasts, conditions concerning grid availability. The objective is the optimization of the power flow taking into account grid cost, prediction, data, grid power limitations, and storage capability. The power flow is optimized by mixed-integer linear programming, described using Java language solved by CPLEX solver. In this optimization, we take into consideration only the energy management layer [7].

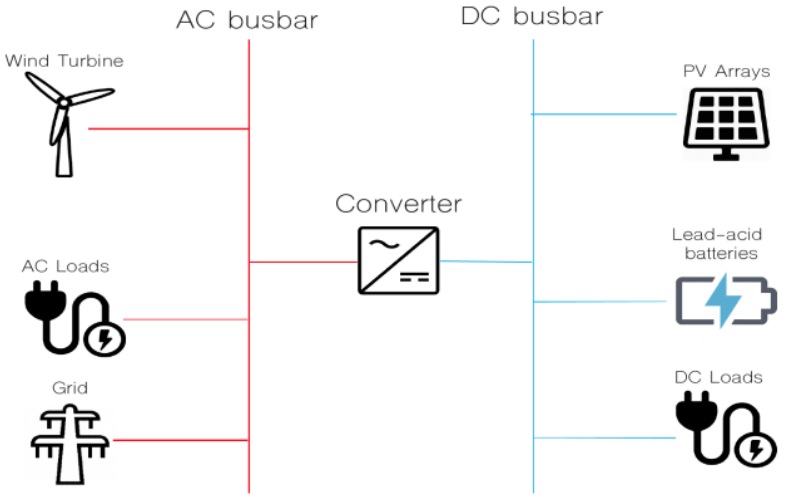

Fig.1. General overview of hybrid AC/DC microgrid.

\section{A. Hybrid Control System(HCS)}

A detailed description was provided of how to use the Hybrid Control System (HCS) including the global optimization methodology [8]. The goal wish is the minimizing energy cost respecting all factors of the performance system. To be brief, HCS is composed of four layers, wish are: the client layer wish offers the interface which facilitates the users to select the criteria suitable to their need, the prediction layer wish predicts RESs production and load consumption, the optimization power flow is ensured with the aid of the energy management layer,

Published By:

Blue Eyes Intelligence Engineering \& Sciences Publication

(C) Copyright: All rights reserved.

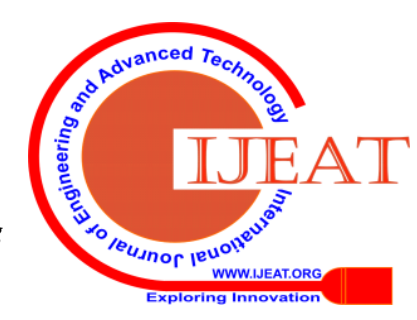


and local layer wish is used to transfer the upper-level strategy's guidelines to the lower level. In figure 2, the HCS is described as a multi-layer design interacting with the multi-source system. To be brief, HCS is composed of four layers [9] [10]:

1) The client layer wish presents the human-machine interface.

2) The prediction layer wish predicts RESs production and load consumption

3) The energy management layer wish to optimize the power flow, and,

4) The local layer which is used to transfer the upper-level strategy's guidelines to the lower level.

Hybrid Control System

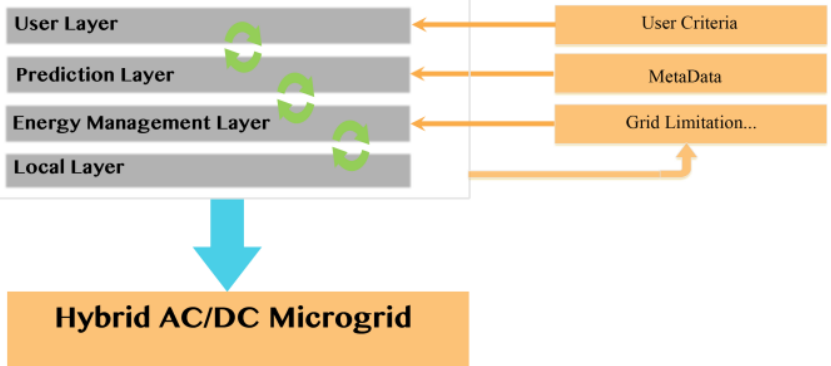

Fig. 2. Schematic diagram of hybrid control system (HCS).

\section{B. Energy Management Layer}

In the present study, we are concerned only in the energy management layer (EML), described in figure 3, and it has the objective of resolving an optimization hassle to determine the hourly power output of each disposable RESs for the next day, by considering the power generation and consumption. EML is mainly focused on economics, considering factors like capital costs, maintenance and energy costs, lifetimes, etc. [11] [12] [13].

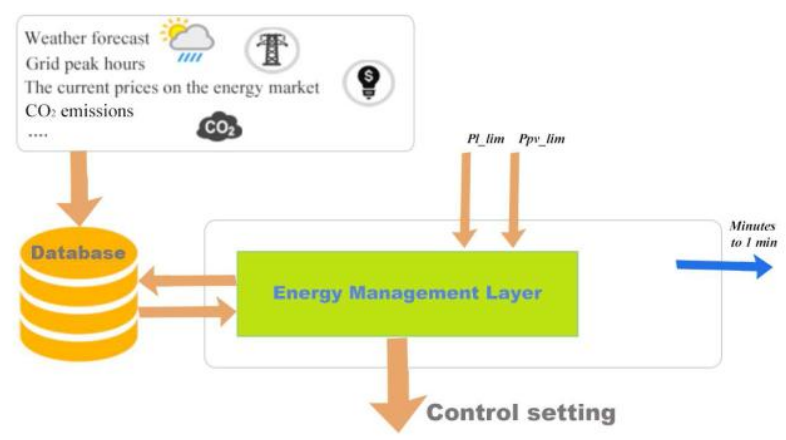

Fig. 3. Energy Management Layer.

\section{SUPERVISION STRATEGY OVERVIW}

Overall power management of different RESs in a multi-source electrical system is needed. When the grid-tied mode is activated, the principal goal of the proposed HMG is: lowering grid height consumptions, keeping off undesired grid power injection, and decreasing energy cost. When the RESs are not able to produce sufficient power (PV arrays and wind powers are low), Then is essential to use batteries to meet load power demand. When the SOC of the battery in minimal value $45 \%$, the increase of HCS performance requires the achievement of effective management of the interaction in the functioning of the various tools and devices [14].

\section{A. Constraints}

\section{A.1 RESs limits}

The renewable energy sources of the HMG consist of:

- The PV arrays connected to the DC bus as mentioned in figure 1 , have two operation modes: MPPT mode and normal constant voltage mode.

- The wind turbine generator connected to the AC bus. To guarantee the proper functioning of the system, the power produced should be maintained within the convenient constraints. Therefore, the output power of RESs must be limited, however, it should not induce negative power to prevent any damage and maximize the lifetime of the devices [15]:

$P_{P V}(t) \geq 0, P_{W T}^{A C}(t) \geq 0$

\section{A.2 Energy storage system (ESS)}

ESS is a basic part of MGs, because it provides a back-up to the intermittence of the RESs, contributing to the HMG balance and reliability. The capability of the ESS is related to the ultimate calculated state of the charge (SOC) and to the system operating in the meantime from $\mathrm{t}-1$ to $\mathrm{t}$. In fact, the SOC must be limited by constraints [16].

$S O C_{M I N}(t) \leq S O C(t) \leq S O C_{M A X}(t)$

Where $S O C_{M I N}(t), S O C_{M A X}(t)$ are the maximum and minimum limitations of storage capacities. The $\operatorname{SOC}(t)$ model can be estimated:

$\operatorname{SOC}(t)=\operatorname{SOC}\left(t_{0}\right)+\frac{1}{720} \times \frac{\eta_{B}}{C_{N} \times V_{B U S}} \times$

$\int_{t_{0}}^{t}\left(P_{B_{C}}(\mathrm{t})-P_{B_{-} D}(\mathrm{t})\right) d t$

$\operatorname{SOC}\left(t_{0}\right)$ is the initial value of $\operatorname{SOC}(t)$ at time $t_{0}, C_{N}$ as nominal battery capacity measured in Ah. $V_{B U S}$ which defines the DC bus voltage. When the battery is not sufficiently charged, the RESs (PV arrays and wind turbine) production should not be stopped or limited. The ESS has two principle parameters:

- $P_{B \_}$: the charging power of the batteries;

- $P_{B_{-} D}$ : the discharging power of the ESS.

Finally, the power of batteries is limited by $P_{B C}^{\max }(t)$ and $P_{R D}^{\min }(t)$.

$P_{B C}^{\max }(t) \leq P_{B}(t) \leq P_{R D}^{\min }(t)$

\section{A.3 Grid Control}

The standard microgrid has the advantage of purchasing electricity and selling it again to the grid network. Moreover, the purchase and sale costs of power are decided in real-time from loads demand variation during the day. Finally, the control of power demand depends on a rate parameter, denoted as $T(t)$ in $\$ / \mathrm{kWh}$, who varies periodically with wholesale market prices.

$P_{G}(t)$ is the utility grid power:

- If $P_{G}(t) \geq 0$ : the power is imported from the grid, and

- If $P_{G}(t)<0$ : the power is exported to the grid.

To reliably operate the utility grid, the power exchanged

Published By:

Blue Eyes Intelligence Engineering

\& Sciences Publication

DOI: 10.35940/ijeat.D6699.049420

Journal Website: www.ijeat.org

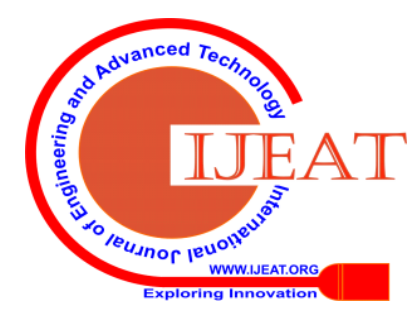


should be limited by the following limits.

$P_{G_{-} M I N}(t) \leq P_{G}(t) \leq P_{G_{-} M A X}(t)$

\section{A.4 Loads}

The power consumption due to the load connected to the HMG can be represented in a general form as:

$$
P_{L_{-} M I N}(t) \geq P_{L}(t) \geq P_{L_{-} M A X}(t)
$$

Where $P_{L}, P_{L_{-} M I N}, P_{L_{-} M A X}$ are respectively load power, minimum power and maximum power of load.

\section{B. Power Balancing}

Power balancing is a crucial aspect in the HMG, increasing the reliability of a multi-source power system and allowing high stability of microgrid voltage. Therefore, the hybrid microgrid operation constraints are classified as DC side and AC side. The power balance equation on the DC side of the HMG is expressed as [17]:

$M G^{D C}: P^{*} \times \eta^{*}+P_{L}^{D C}(t)=$

$\left(P_{P V}(t) \times \eta_{P V}+P_{W T}^{A C}(t) \times \eta_{W T}^{A C}\right)-P_{B}(\mathrm{t}) \times \eta_{B}$

Where $\mathrm{P}^{*}$ is the power exchanged between two sides of the HMG (AC and DC buses). The power balance equation at the AC part of the hybrid microgrid is:

$M G^{A C}: \eta_{G} \times P_{G}(t)=P_{L}^{A C}(t)+P^{*}(t) \times \eta^{*}$

The system takes into consideration three principles situations:

1) The energy generated by RESs (PV arrays and wind) meets the specified load demand,

2) The total energy power generated by HMG (RESs and batteries) is not sufficient to meet the power consumed by the loads, and,

3) The energy produced is more than the need for power consumed by the HMG.

In the present paper, two parameters are taken into account:

$P_{p}(t)=P_{P V}(t) \times \eta_{P V}+P_{W T}^{D C}(t) \times \eta_{W T}^{D C}$
$P_{L}(t)=P_{L}^{A C}(t)+P_{L}^{D C}(t)$

With $P_{p}$ is the total power produced by the RESs and $P_{L}$ is the total load demand in the HMG. The time step is: $t$ $\in\left\{t_{0}, t_{0}+1, \ldots, t_{0}+n \Delta \tau\right\}$.

In the first case, when the power produced by RESs meets the required load demand, the electricity generated via the RESs is identical to the total energy demand $\left(P_{p}(t)=P_{L}(t) / \eta_{I n}\right)$. Then, the power system will not inject any power to the grid or purchase power from the network and the battery bank keeps a stable value during this operation, so: $P_{G}^{\text {sell }}(\mathrm{t})=P_{G}^{\text {buy }}(\mathrm{t})=0, \quad P_{B}(\mathrm{t})=P_{B}(\mathrm{t}+1)$

2) In that case, the produced energy of the RESs is more than what's demanded $\left(P_{p}(t)>P_{L}(t) / \eta_{\text {Inv }}\right)$ :

The surplus power available for charging the batteries:

$P_{B}(\mathrm{t})=P_{B}\left(t_{0}\right)+\int_{t_{0}}^{t}\left[\left(P_{p}(t)-P_{L}(t) / \eta_{I n v}\right)\right] \times \eta_{B_{-} C} d t$

$P_{G}^{\text {buy }}(\mathrm{t})=0$

$\eta_{B_{-} C}$ is the battery efficiency in charging mode. $\eta_{I n v}$ is the DC/AC efficiency, and in this study, its default value as $90 \%$, If the excess energy of the RESs after the batteries being charged, this power may be sold to the grid:

$P_{G}^{\text {sell }}(\mathrm{t})=\frac{\eta_{G}}{720 \times \eta_{B_{-} D}} \int_{t_{0}}^{t}\left[\left(P_{B}(\mathrm{t}+1)-P_{B}^{\max }\right)\right] \times \eta_{B} d \mathrm{t}$

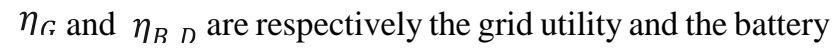
in discharging mode efficiency. $P_{R}^{\max }$ is the maximum of power reached by the storage system.

3 ) When the energy produced is more than the need of power by the HMG $\left(P_{p}(t)<P_{L}(t) / \eta_{I n v}\right)$. So, there are two possibilities:

a) The total energy provided by RESs and batteries can satisfy the need of power

$$
\begin{aligned}
& \left(P_{p}(t)+\frac{1}{720}\left(P_{B}(\mathrm{t})-P_{B}^{\text {min }}\right) \times \eta_{B_{-} D}>P_{L}(t) / \eta_{I n \nu}\right): \\
& P_{B}(\mathrm{t})=P_{B}\left(t_{0}\right)+ \\
& \int_{t_{0}}^{t}\left[\left(P_{p}(t)-P_{L}(t) / \eta_{I n v}\right)\right] \times \frac{1}{\eta_{B_{-} D}} d \mathrm{t} \\
& P_{G}^{\text {sell }}(\mathrm{t})=P_{G}^{\text {buy }}(\mathrm{t})=0
\end{aligned}
$$

Where $\eta_{B_{-} D}$ is the battery efficiency in discharging mode, and in the present study, the value that was taken is $90 \%$.

b) The to be had power stored within the batteries and the energy generated by the RESs can't meet the demand. Hence, the batteries are completely discharged and the overall produced electricity (PV Arrays + wind + batteries) can't satisfy the devices power requirements, accordingly, the required power $P_{G}^{b u y}(t)$ will be bought from the grid $\left(P_{p}(t)+\frac{1}{3600}\left(P_{B}(\mathrm{t})-P_{B}^{\min }\right) \times \eta_{B}<P_{L}(t) / \eta_{\text {In }}\right):$

$P_{G}^{b u y}(\mathrm{t})=\frac{1}{720 \times \eta_{B_{-} D} \times \eta_{G}}$

$\int_{t_{0}}^{t}\left[\left(P_{L}(t) / \eta_{I n v}-P_{p}(t)-\left(P_{B}(\mathrm{t})-P_{B}^{\min }\right)\right)\right] d 1$

$P_{G}^{\text {sell }}(\mathrm{t})=0$

\section{Optimization algorithm}

The principle goal of this work is minimizing the total cost and maximizing the lifetime of the HMG with a smooth exchange of energy between the power system and the grid [18]. In this case, the development of an algorithm to improve

\begin{tabular}{|c|c|c|}
\hline Parameters & Power tariff of: & Value \\
\hline Tpv & PV Arrays & $0.5 \$ / \mathrm{kWh}$ \\
\hline Twt & Wind Turbine & $0.5 \$ / \mathrm{kWh}$ \\
\hline $\mathrm{Tb}$ & Battery & $0.1 \$ / \mathrm{kWh}$ \\
\hline $\mathrm{Tl}$ & Electricity loads & $0.5 \$ / \mathrm{kWh}$ \\
\hline Tgb & Purchased energy & $\begin{array}{l}0.1 \$ / \mathrm{kWh} \text { and } \\
0.5 \$ / \mathrm{kWh} \text { in peak } \\
\text { hours }\end{array}$ \\
\hline Tgs & Sold energy & $\begin{array}{l}0.1 \$ / \mathrm{kWh} \text { and } \\
0.8 \$ / \mathrm{kWh} \text { in peak } \\
\text { hours }\end{array}$ \\
\hline
\end{tabular}
the performance index in order to obtain an optimal control strategy for the power system is needed [19].

Table-I: Description of objective function parameters.

Published By:

Blue Eyes Intelligence Engineering

\& Sciences Publication

(C) Copyright: All rights reserved.

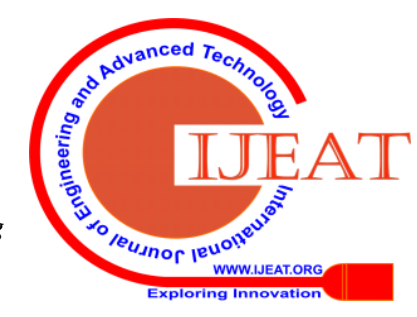


The minimum values of the overall performance index indicate decrease energy charges and optimize management policies. The overall performance index, that's also known as objective or price function. The objective function is the sum of all the system cost. Table 1 describes the parameters of the objective formula [20]:

$$
C s(t)=C p v(t)+C w t(t)+C b(t)+C l(t)+C g(t)
$$

Where $C p v$ is PV Array cost, $C w t$ is wind cost, $C b$ is battery cost, $C l$ is load cost and $C g b, C g s$ are the price for the purchased power from the grid and the sold electricity to the grid. The costs are defined by the following equations:

$$
\begin{aligned}
& C_{p v}(t)=\sum_{t=0}^{t f}\left[\left(P_{p v_{-m p p t}}(t i)-P_{p v}(t i)\right)^{*} T_{p v}\left(t_{i}\right)\right] \delta \mathrm{t} \\
& C_{w t}(t)=\sum_{t=0}^{t f}\left[\left(P_{w t_{-m p p t}}(t i)-P_{w t}(t i)\right)^{*} T_{w t}\left(t_{i}\right)\right] \delta \mathrm{t} \\
& C_{b}(t)=\sum_{t=0}^{t f}\left[\left(P_{b c}(t i)-P_{b d}(t i)\right)^{*} T_{b}\left(t_{i}\right)\right] \delta \mathrm{t} \\
& C_{l}(t)=\sum_{t=0}^{t f}\left[P_{l}(t i) * T_{l}\left(t_{i}\right)\right] \delta \mathrm{t} \\
& C_{g}(t)=\sum_{t=0}^{t f}\left[\left(P_{g b}(t i) * T_{g b}\left(t_{i}\right)-P_{g s}(t i)^{*} T_{g s}\left(t_{i}\right)\right)\right] \delta \mathrm{t}
\end{aligned}
$$

The optimization problem may be mathematically expressed by:

$$
\begin{aligned}
& M G^{A C}: \eta_{G} \times P_{G}(t)=P_{L}^{A C}(t)+P^{*}(t) \times \eta^{*} \\
& M G^{D C}: P^{*} \times \eta^{*}+P_{L}^{D C}(t)= \\
& \left(P_{P V}(t) \times \eta_{P V}+P_{W T}^{A C}(t) \times \eta_{W T}^{A C}\right)-P_{B}(\mathrm{t}) \times \eta_{B} \\
& P_{p}(t)=P_{P V}(t) \times \eta_{P V}+P_{W T}^{A C}(t) \times \eta_{W T}^{A C}, \\
& P_{L}(t)=P_{L}^{A C}(t)+P_{L}^{D C}(t) \\
& \text { - If } P_{p}(t)>P_{L}(t) / \eta_{\text {Inv }} \\
& P_{B}(\mathrm{t})=P_{B}\left(t_{0}\right)+\int_{t_{0}}^{t}\left[\left(P_{p}(t)-P_{L}(t) / \eta_{I n v}\right)\right] \times \eta_{B_{-} C} \\
& d \mathrm{t}, \mathrm{t} \in\left\{t_{f}, t_{0}+1, \ldots, t_{0}+n \Delta \tau\right\} \\
& P_{G}^{\text {sell }}(\mathrm{t})=\frac{\eta_{G}}{720 \times \eta_{B_{-} D}} \int_{t_{0}}^{t}\left[\left(P_{B}(\mathrm{t}+1)-P_{B}^{\max }\right)\right] \times \eta_{B} d \mathrm{t} \\
& \text {, } P_{G}^{b u y}(\mathrm{t})=0, P_{B}(\mathrm{t})=P_{B}^{\max } \\
& \text { - If } P_{p}(t)=P_{L}(t) / \eta_{\text {Inv }} \\
& P_{G}^{\text {sell }}(\mathrm{t})=P_{G}^{b u y}(\mathrm{t})=0, \quad P_{B}(\mathrm{t})=P_{B}(\mathrm{t}+1) \\
& \text { - If } P_{p}(t)<P_{L}(t) / \eta_{\text {Inv }} \\
& \text { 1) } P_{p}(t)+\frac{1}{720}\left(P_{B}(\mathrm{t})-P_{B}^{\min }\right) \times \eta_{B_{-} D}> \\
& P_{L}(t) \eta_{\eta_{\text {Inv }}} \\
& P_{B}(\mathrm{t})=P_{B}\left(t_{0}\right)+\int_{t_{0}}^{t}\left[\left(P_{p}(t)-P_{L}(t) / \eta_{\text {Inv }}\right)\right] \times \frac{1}{\eta_{B_{-} D}} \\
& d \mathrm{t}, P_{G}^{\text {sell }}(\mathrm{t})=P_{G}^{\text {buy }}(\mathrm{t})=0
\end{aligned}
$$

2) $P_{p}(t)+\frac{1}{720}\left(P_{B}(\mathrm{t})-P_{B}^{\min }\right) \times \eta_{B}<$

$$
P_{L}(t) / \eta_{\text {Inv }}
$$

$P_{G}^{b u y}(\mathrm{t})=\frac{1}{720 \times \eta_{B_{-} D} \times \eta_{G}}+$

$\int_{t_{0}}^{t}\left[\left(P_{L}(t) / \eta_{I n v}-P_{p}(t)-\left(P_{B}(\mathrm{t})-P_{B}^{\min }\right)\right)\right] d \mathrm{t}$

$P_{B}(\mathrm{t}+1)=P_{B}^{\min }, P_{G}^{\text {sell }}(\mathrm{t})=0$

$\operatorname{SOC}(t)=\operatorname{SOC}\left(t_{0}\right)+\frac{1}{720} \times \frac{\eta_{B}}{C_{N} \times V_{B U S}} \times$

$\int_{t_{0}}^{t}\left(P_{B_{C}}(\mathrm{t})-P_{B_{-} D}(\mathrm{t})\right) d \mathrm{t}$

$S O C_{M I N}(t) \leq S O C(t) \leq S O C_{M A X}(t)$

$P_{G_{-} M I N}(t) \leq P_{G}(t) \leq P_{G_{-} M A X}(t), P_{P V}(t) \geq 0$,

$P_{P V}(t) \geq 0, P_{W T}^{D C}(t) \geq 0 P_{W T}^{A C}(t) \geq 0$,

$P_{L_{-} M I N}(t) \leq P_{L}(t \leq) P_{L_{-} M A X}(t)$

subject to

$\min C p v(t)+C w t(t)+C b(t)+C l(t)+C g(t)$

\section{SIMULATION RESULTS}

For the experimental simulation of the HMG we used HOMER energy modeling software, then, based on the numerical result provided by Homer, we tested the feasibility of the proposed optimization algorithm below to ensure optimal management of the power system. The simulation of the wall management method in grid-tied mode is based on the climate condition of the 19th of January 2019 in Rabat, Morocco. The energy management layer has the position to calculate the optimization hassle via CPLEX and Java language under Eclipse IDE software to ensure an optimal energy control (figure 4).

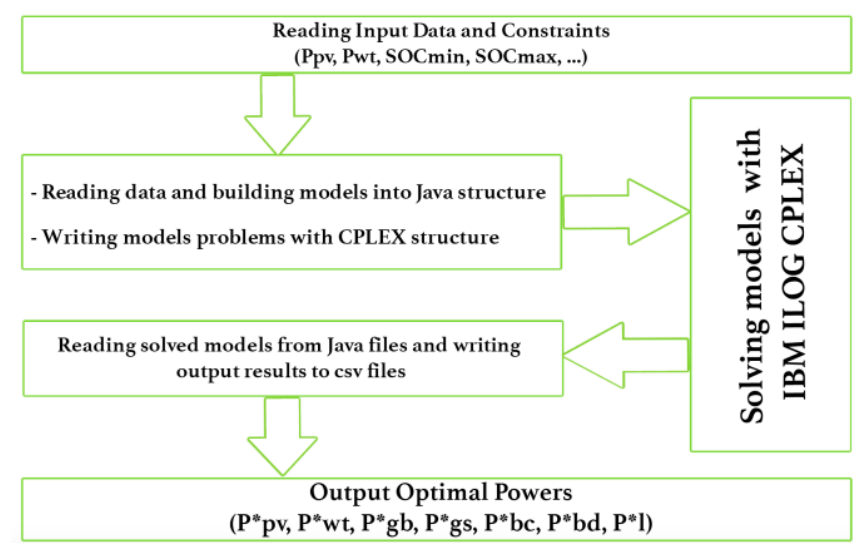

Fig. 4. Description of optimization method.

For a conceptual model of HMG, we use the software Homer system platform, for that we don't take into account the individual modeling of each component of the power system and the numerical values of the output powers more than having a realistic approach to resolve the real studied problem. The simulation results of the HMG are obtained using Eclipse IDE combined with MATLAB-Simulink.

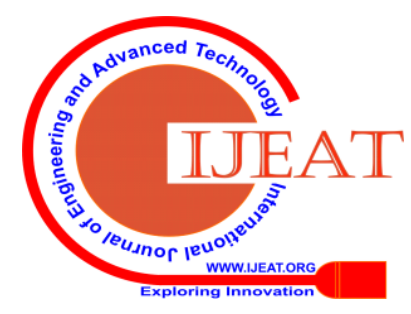




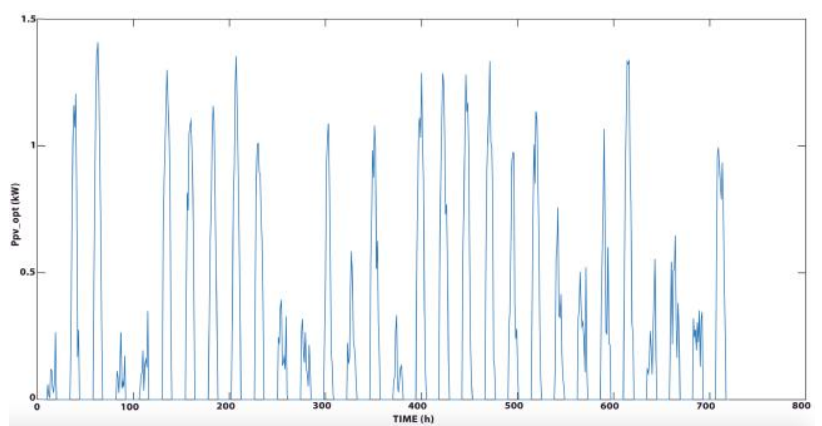

Fig. 5. Optimal Output power of the PV Arrays.

Figures 5 and 6 show the optimal output power simulated for the PV Arrays and the wind, respectively.

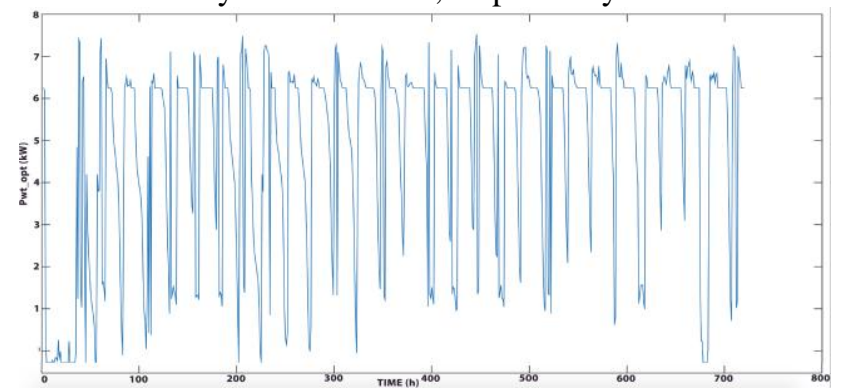

Fig. 6. Optimal Output power of the wind.

Figure 7 shows the total of AC and DC load demand of the HMG in each hour. At the time 525 (21 January at $10 \mathrm{pm}$ ), the peak load took place $(4 \mathrm{~kW})$, during this time the wind power produced $(7.5 \mathrm{~kW})$ can satisfy the peak load consumption. Therefore, the batteries are not used and the HMG injects the power to the grid with minimal value.

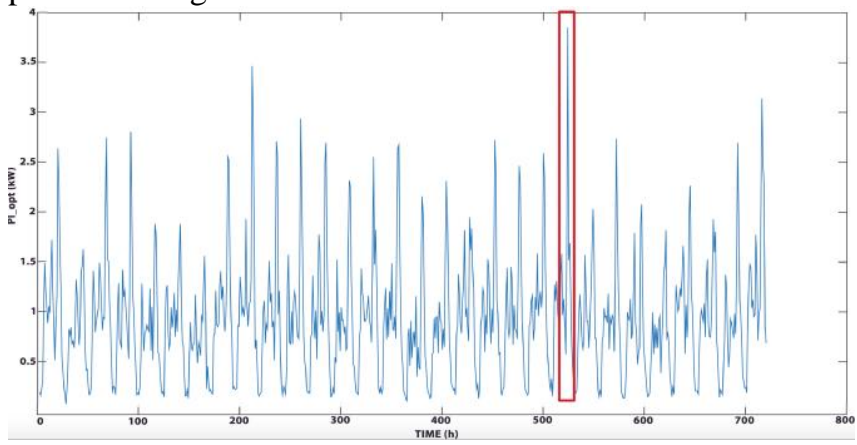

Fig. 7. Load profile.

ESS can be used at the time between 520 and 610 to supplement a shortage of primary RESs to meet load demand, as well as produce energy at peak load demand (at the time 580 ). As shown in figure 8 the energy produced can be stored and used if is necessary by the loads.

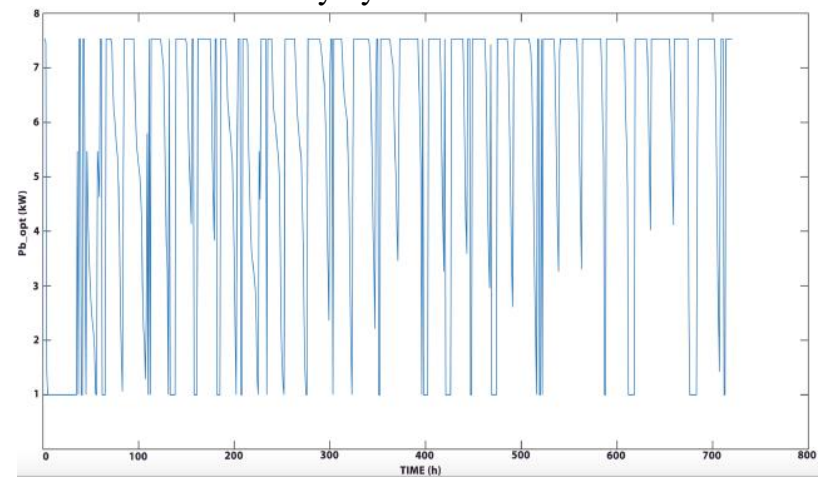

Fig. 8. Battery Output power.

Figure 9 indicates the purchased electricity from the grid and the sold power to the grid for every hour, at the time between 610 and 618 (25 January at night) the RESs and battery bank can't satisfy the load demand $(0.9 \mathrm{~kW})$. At this time, the HMG purchased the power from the grid.

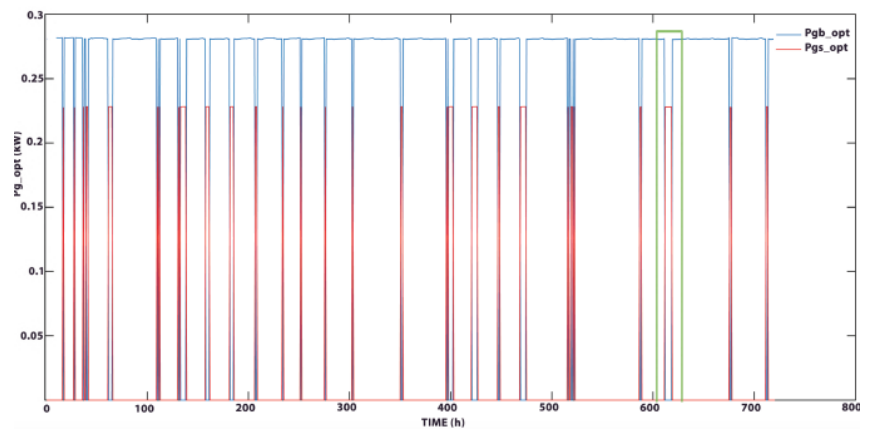

Fig. 9. Optimal grid power.

The general operating value of the HMG thinking about the consequences purchased power from the grid, and the sold electricity to the grid is equal to $\$ 45,740$.

\section{CONCLUSION}

The present work is being carried out on smart control strategy for HMG. The HCS provides the online set information for generating units while reducing the operational cost and considering the forecast of RESs, storage system and loads. The average operational costs of the power system (PV/Wind/ESS) are reduced because of minimization in the energy deficit which leads to better control of the ESS. The proposed supervision system (HCS) during this study proves a new vision of optimal optimization of an HMG with limited access to the utility grid and the option of selling power in case of energy self-sufficiency, by taking into account the personal criteria of end-users as well as the forecast of the energy production of the HMG, the climatic criteria and also some specific constraints such as grid power limitations, storage capacity, energy prices, and grid peak hours. To solve the optimization problems was CPLEX mixed integer optimizer with Java language was a perfect solution. Despite the lack of precision of the weather forecast and the random changes of the energy price on the market, the results of simulation, taken as hypotheses in this study, indicate that the proposed supervision design can function effectively in grid-connected mode and optimize the system performance. in real-time, taking into account several constraints such as peak hours and the instability of power production of RESs. The simulation result validate perfectly the total cost reduction of the HMG.

\section{REFERENCES}

1. S.R. Cominesi, A.L. Bella, M. Farina, R. Scattolini, "A multi-layer control scheme for microgrid energy management", IFAC-PapersOnLine, Vol. 49, pp. 256-261, 2016.

2. C. Suchetha, J. Ramprabhakar, "Optimization Techniques for Operation and Control of Microgrids - Review", Journal of Green Engineering, Vol. 84, pp. 621-644, 2018.

3. A.D. Bintoudi, L. Zyglakis, T. Apostolos, D. Ioannidis, S.A. Agtash, J.L.M. Ramos, D. Tzovaras, "Novel hybrid design for microgrid control", IEEE PES Asia-Pacific Power and Energy Engineering Conference (APPEEC), 2017.

4. P. Wu,W. Huang, N. Tai, Z. Ma, X. Zheng, Y. Zhang, "A Multi-layer Coordinated Control Scheme to Improve the Operation Friendliness of Grid-Connected Multiple Microgrids”, Energies, 2019.

5. E.E. Lee, W. Shi, R. Gadh, W. Kim, "Design and Implementation of a Microgrid Energy Management System”, Sustainability, 2016.

Published By:

Blue Eyes Intelligence Engineering

\& Sciences Publication

(C) Copyright: All rights reserved.

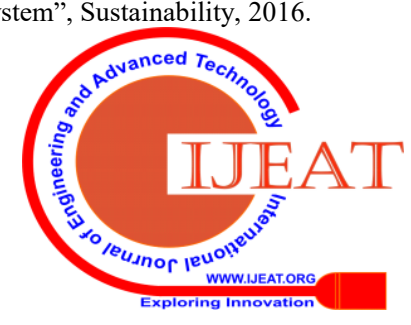


6. N. Qachchachi, H. Mahmoudi, A.E Hasnaoui, "Smart hybrid AC/DC microgrid: Power management based Petri Nets", International Conference on Information Technology for Organizations Development, 2016.

7. X. Xing, H. Meng, L. Xie, P. Li, S. Toledo, Y. Zhang, J.M. Guerrero, "Multi-time-scales energy management for grid-on multi-layer microgrids cluster", IEEE Southern Power Electronics Conference, 2017.

8. N. Qachchachi, H. Mahmoudi, A.E Hasnaoui, “Optimal power flow for a hybrid AC/DC microgrid”, International Renewable and Sustainable Energy Conference, 2014.

9. X. Jianfang, W. Peng, L. Setyawan, J. Chi, C.F. Hoong, "Energy management system for control of hybrid AC/DC microgrids", IEEE 10th Conference on Industrial Electronics and Applications, 2015.

10. D. Leskarac, M. Moghimi, J. Liu, W. Water, J. Lu, S. Stegen, "Hybrid AC/DC Microgrid testing facility for energy management in commercial buildings", Energy and Buildings, Vol. 174, pp. 563-578, 2018.

11. E. Unamuno, J. Barrena," Hybrid ac/dc microgrids-Part II: Review and classification of control strategies", Renewable and Sustainable Energy Reviews, Vol. 52, pp. 1123-1134, 2015.

12. V. Indragandhi, R. Logesh, V. Subramaniyaswamy, V. Vijayakumar, Patrick Siarry, Lorna Udene," Multi-objective optimization and energy management in renewable based AC/DC microgrid", Computers and Electrical Engineering journal, 2018.

13. J. Hu, Y. Shan, Y. Xu, J.M. Guerrero,” A coordinated control of hybrid ac/dc microgrids with PV-wind-battery under variable generation and load conditions", International Journal of Electrical Power and Energy Systems, Vol. 104, pp. 583-592, 2019.

14. K. Hristiyan, C. Frederic, L. Vladimir, F. Bruno," Emission reduction and economical optimization of an urban microgrid operation including dispatched PV-based active generators", IEEE Transactions on Sustainable Energy, Vol. 5, No. 4,2014.

15. L.T. Dos Santos, M. Sechilariu, F. Locment," Prediction-based optimization for islanded microgrid resources scheduling and management". IEEE 24th International Symposium on Industrial Electrdonics, 2015.

16. L. Jiaxin, W. Weijun, Y. Zhang, S. Cheng," Multi-Objective Optimal Design of Stand-Alone Hybrid Energy System Using Entropy Weight Method Based on HOMER", Energies, 2017.

17. J. Wu, Z. Wu, F. Wu, X. Mao," A power balancing method of distributed generation and electric vehicle charging for minimizing operation cost of distribution systems with uncertainties", Energy Science an Engineering, Vol. 5, pp. 167-179, 2017.

18. X. Zhang, R. Sharma, H. Yanyi," Optimal energy management of a rural microgrid system using multi-objective optimization", IEEE PES Innovative Smart Grid Technologies, 2012.

19. Y. Zhu, F. Wang, K. Liu," Operating mode analysis of hybrid AC/DC microgrids", Journal of Physics: Conference Series, 2018.

20. M.E. Hendawi, H. Gabbar, G.E. Saady, E. Ibrahim," Control and EMS of a Grid-Connected Microgrid with Economical Analysis", Energies 11, 2018.

\section{AUTHORS PROFILE}

Qachchachi Nabil Electrical Engineering Department, Mohammedia Engineering School, Mohammed-V University, Rabat, Morocco.

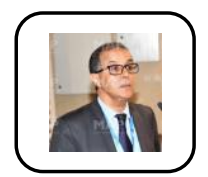

Mahmoudi Hassane Electrical Engineering Department, Mohammedia Engineering School, Mohammed-V University, Rabat, Morocco.

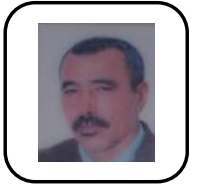

Abdennebi El Hasnaoui Electromechanical Department, Rabat School of Mines, Rabat, Morocco.

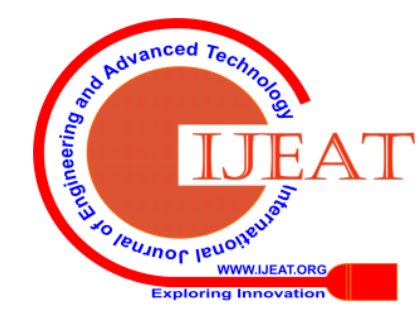

